ARTIGO ORIGINAL

\title{
Rendimento e qualidade da madeira de Eucalyptus benthamii Maiden et Cambage de rotação longa no processo de desdobro
}

\author{
Efficiency and quality of Eucalyptus benthamii Maiden et Cambage wood \\ of long rotation in the sawing process
}

\author{
Gustavo Faggiani Tomio ${ }^{1}$ (D), Alexsandro Bayestorff da Cunha ${ }^{1}$ (D), Martha Andreia Brand ${ }^{1}$ (D), \\ Ulisses de Arruda Córdova ${ }^{(1)}$ \\ ${ }^{1}$ Universidade do Estado de Santa Catarina - UDESC, Lages, SC, Brasil \\ ${ }^{2}$ Empresa de Pesquisa Agropecuária e Extensão Rural de Santa Catarina - EPAGRI, Lages, SC, Brasil
}

Como citar: Tomio, G. F., Cunha, A. B., Brand, M. A., \& Córdova, U. A. (2021). Rendimento e qualidade da madeira de Eucalyptus benthamii Maiden et Cambage de rotação longa no processo de desdobro. Scientia Forestalis, 49(132), e3689. https://doi.org/10.18671/scifor.v49n132.01

\section{Resumo}

Estudos com espécies que toleram o frio e geadas, como o Eucalyptus benthamii, vem sendo desenvolvidos nos últimos anos. No entanto, as pesquisas e informações disponíveis, estão relacionadas à silvicultura e caracterização tecnológica da madeira de ciclos médios e curtos, o que tem proporcionado desvalorização da espécie e insatisfação por partes dos reflorestadores. O objetivo do estudo foi avaliar a influência da classe diamétrica e do método de desdobro no rendimento da conversão mecânica de toras de E. benthamii, provenientes de árvores com ciclo de rotação longa (23 anos), e a qualidade da madeira produzida. Foram utilizadas árvores de um plantio experimental, localizado na cidade de Lages, Santa Catarina. O plano experimental foi caracterizado por quatro classes diamétricas e dois métodos de desdobro. Foi determinado o rendimento do processo, sendo as peças de madeira serrada classificadas em cinco grupos de qualidade, conforme NBR 14806 (ABNT, 2002). O rendimento do desdobro foi influenciado pela classe diamétrica e pela sua interação com o método de desdobro, com maiores aproveitamentos nas classes superiores e no método tangencial. A maior parte das peças foram classificadas como 4 e 5, devido à presença de fendilhamentos, nós cariados e veios de resina. Quanto as dimensões, toras com maiores diâmetros e desdobradas pelo método tangencial, produziram peças mais largas; enquanto que a espessura não foi afetada pelas variáveis mencionadas. A utilização de toras de E. benthamii, provenientes de árvores com rotação longa, mostrou-se viável no desdobro, com rendimento equivalente a grande parte das espécies de rápido crescimento.
\end{abstract}

Palavras-chave: espécie de eucalipto com tolerância ao frio e a geada; processamento mecânico; classe diamétrica e método de desdobro; madeira serrada; classes de qualidade.

\begin{abstract}
Studies with species that tolerate cold and frosts, such as Eucalyptus benthamii, have been developed in recent years. However, the research and information available are related to silviculture and technological characterization of medium and short cycles wood, which has caused devaluation of the species and dissatisfaction_on the part of foresters. The objective of the study was to evaluate the influence of the diametric class and the sawing method on the yield of the mechanical conversion of $E$. benthamii logs, from trees with a long rotation cycle (23 years), and the quality of the wood produced. Three trees of an experimental planting, located in Lages, Santa Catarina were used. The experimental plan was characterized by four diametric classes and two sawing methods. The yield of the process was determined, with the sawn wood pieces classified into five quality groups, according to NBR 14806 (ABNT,
\end{abstract}

Fonte de financiamento: Nada a declarar.

Conflito de interesse: Nada a declarar.

Autor correspondente: alexsandro.cunha@udesc.br

Recebido: 3 março 2021.

Aceito: 8 abril 2021.

Editor: Paulo Henrique Müller Silva.

(c) Este é um artigo publicado em acesso aberto (Open Access) sob a licença Creative Commons Attribution, que permite uso, distribuição e By reprodução em qualquer meio, sem restrições desde que o trabalho original seja corretamente citado. 
2002). The sawing yield was influenced by the diametric class and its interaction with the sawing method, with greater use in the upper classes and in the tangential method. Most parts were classified as 4 and 5 , due to the presence of splits, decayed knots and resin canals. As for the dimensions, logs with larger diameters and sawed by the tangential method, produced wider pieces; while thickness was not affected by the mentioned variables. The use of $E$. benthamii logs from trees with long rotation proved to be viable in sawing, with a yield equivalent to that of most of the fast growing species.

Keywords: eucalyptus species with tolerance to cold and frost; mechanical processing; diametric class and sawing method; sawn wood; quality classes.

\section{INTRODUÇÃO}

O Brasil, devido a seu extenso território e aos climas distintos entre as diversas regiões, possibilita a introdução e o desenvolvimento de inúmeras espécies florestais. No que se refere as espécies do gênero Eucalyptus, sua introdução data do final do século XIX. Desde então, as áreas plantadas vêm crescendo rapidamente, impulsionado pela fácil adaptação (De Vechi \& Magalhães Júnior, 2018).

No início da década de 60, os plantios com espécies de Eucalyptus restringiam-se à produção de postes, lenha, cercas vivas e quebra-ventos. No entanto, a demanda por madeira no Brasil, despertou interesse para serrados.

Entretanto, a madeira das espécies deste gênero, exigem cuidados adicionais em seu processamento, os quais tem impactos na qualidade do produto final. Estes cuidados são justificados pela presença de tensões internas, que afetam as suas propriedades, e consequentemente, o seu processamento e usos, especialmente, quando utilizadas árvores com ciclos de rotação médio ou curto.

Até o início do século XXI, toda experiência silvicultural brasileira com espécies do gênero Eucalyptus se resumia na produção de florestas jovens, de ciclo curto e de rápido crescimento. Sendo assim, toda a madeira era utilizada na produção de celulose, carvão vegetal e painéis reconstituídos.

Segundo Silva (2002), a falta de controle da matéria-prima, dos parâmetros de processamento, das experiências na área de serraria com a madeira do gênero Eucalyptus, têm-se mostrado muito restritas. Esse quadro, tem grandes possibilidades de reversão, na medida em que se romperem alguns paradigmas e se aprofundarem os estudos sobre as inúmeras alternativas de uso múltiplo, principalmente na indústria moveleira, construção civil e embalagens.

Além do fato das indústrias utilizarem a madeira com ciclo curto e médio de rotação, a maior parte das pesquisas seguiram a mesma tendência, disponibilizando informações para madeira oriunda de plantios jovens. Pode-se mencionar que as abordagens existentes com a madeira de Eucalyptus se restringem a poucas espécies, como E. grandis, E. urophylla, E. viminalis, E. saligna e o híbrido E. grandis x E. urophylla (Del Menezzi \& Nahuz,1998; Rocha, 2000; Carvalho \& Nahuz, 2001; Rocha \& Tomaselli, 2002; Scanavaca Junior \& Garcia, 2003; Amparado et al., 2008; Anjos \& Fontes, 2017), que se desenvolvem em regiões de clima quente, não se estendendo as que toleram o frio e a geada.

$\mathrm{Na}$ região sul do Brasil, algumas espécies vêm sendo estudadas em plantios experimentais de empresas, institutos de pesquisa e universidades, com intuito de avaliar o desempenho silvicultural e tecnológico, como E. dunnii, E. badjensis e E. benthamii (Rocha, 2000; Rocha \& Tomaselli, 2002; Müller, 2013; Cunha et al.; 2015). Entre estas, destaca-se E. benthamii em função do seu potencial de crescimento e resistência ao frio e a ocorrência de geadas (Silva et al., 2012b).

O E. benthamii é uma espécie nativa da Austrália, implantada no Brasil, mais precisamente nos Estados de Santa Catarina e Paraná pela Embrapa Florestas no ano de 1988. Apresenta rápido crescimento e excelente forma de fuste. Se plantada em época adequada, não é danificada por geadas severas (Silva et al., 2012a).

Segundo Higa \& Pereira (2003), apesar do alto crescimento em diâmetro e altura, o E. benthamii em plantios jovens, possui uma madeira dimensionalmente instável, com índices elevados de retratibilidade, que explicam a alta intensidade de defeitos de 
processo observados no desdobro. Assim, o autor indica a lenha, o carvão e a celulose como usos potenciais da espécie, não sendo aconselhável para serraria. Todavia, as recomendações de uso estão baseadas em plantios jovens e em um número pequeno de amostras.

Assim, salienta-se que apesar da grande divulgação do potencial silvicultural do $E$. benthamii pelas instituições que o trouxeram para o Brasil, e dos esforços na realização de pesquisas para a utilização da espécie; as empresas reflorestadoras, bem como os pequenos e médios proprietários de florestas, não estão satisfeitos com os resultados, o que é justificado pela introdução da espécie em nichos de baixo valor agregado.

O objetivo deste estudo foi avaliar a influência da classe diamétrica e do método de desdobro no rendimento do processo de conversão de toras de E. benthamii, provenientes de árvores com ciclo de rotação longa (23 anos), em peças serradas, bem como a qualidade da madeira produzida.

\section{MATERIAL E MÉTODOS}

As árvores de E. benthamii foram provenientes de um plantio experimental com 23 anos, localizado na Estação Experimental da Empresa de Pesquisa Agropecuária e Extensão Rural de Santa Catarina (EPAGRI), de Lages, Santa Catarina. Foram disponibilizadas pela empresa, cinco árvores com altura total média de 37,16 m, altura comercial de 31,36 m e DAP de $49 \mathrm{~cm}$.

O plantio experimental foi implantado em 1994, com objetivo de observar o crescimento e a adaptação da espécie ao clima local para a colheita de sementes potenciais. As árvores em total de 30, foram plantadas em espaçamento $3 \mathrm{~m} \times 3 \mathrm{~m}$ em 5 filas, com 6 árvores em cada uma delas. O solo do local é descrito como distrófico álico, sendo feito apenas uma adubação com $200 \mathrm{~g}$ de NPK (50-20-10) por cova, antes da inserção das mudas.

Após a derrubada das árvores, com motosserra, foi realizada a marcação das posições de retirada dos toretes para classificação e desdobro, a qual foi iniciada em 1,30 m devido ao desenvolvimento de outros estudos com a madeira retirada até esta altura. Foram cortados toretes com 2,40 m de comprimento até o diâmetro médio mínimo de $23,7 \mathrm{~cm}$, gerando em média 7 toretes por árvore.

Foram medidos em cada um dos toretes, o comprimento e os diâmetros das extremidades, de modo a determinar o volume pelo método de Smalian e realizar a distribuição em quatro classes diamétricas, Dentro de cada classe, foram estabelecidas duas subclasses em função do método de desdobro empregado.

Desta forma, o delineamento experimental (Tabela 1) foi caracterizado como inteiramente casualizado com quatro fatores (classe diamétrica) e dois níveis (métodos de desdobro), totalizando 8 tratamentos. Em cada tratamento, foram utilizadas 4 toras, as quais foram consideradas como repetições.

Tabela 1 - Plano experimental para classe diamétrica e método de desdobro.

\begin{tabular}{ccc}
\hline Tratamento & Classe Diamétrica & Método de Desdobro \\
\hline 1 & A & Tangencial \\
2 & $(23,7-30,6 \mathrm{~cm})$ & Radial \\
3 & B & Tangencial \\
4 & $(30,7-34,8 \mathrm{~cm})$ & Radial \\
5 & $C$ & Tangencial \\
6 & $(34,9-40,7 \mathrm{~cm})$ & Radial \\
7 & $D$ & Tangencial \\
8 & $(40,8-54,5 \mathrm{~cm})$ & Radial \\
\hline
\end{tabular}

No método tangencial, as toras foram desdobradas de forma alternada em uma serra fita simples, onde foram retiradas duas costaneiras de espessura reduzida, que não foram 
reaproveitadas. Posteriormente, o semi-bloco foi tombado e desdobrado simultaneamente em uma serra circular múltipla de dois eixos.

No radial, as toras também foram desdobradas em uma serra fita simples, onde foram obtidos um semi-bloco central e duas costaneiras de espessura reduzida, com intuito de reduzir o efeito das tensões de crescimento no corte posterior. O semi-bloco foi tombado e cortado ao meio na mesma serra, gerando dois semi-blocos menores, os quais foram processados radialmente em uma serra circular múltipla de dois eixos.

As dimensões das peças de madeira serrada obtidas no desdobro das toras, por ambos os métodos, foram de 25,4 mm de espessura, largura variável conforme o diâmetro de cada tora e comprimento de $2,40 \mathrm{~m}$.

A avaliação quantitativa do processo de desdobro foi realizada pela determinação do rendimento em peças de madeira serrada, por meio da relação entre o somatório dos volumes das peças e o volume de cada tora utilizada para a operação. O volume de cada peça foi determinado por meio da medição de três espessuras e três larguras ao longo do comprimento.

A avaliação qualitativa consistiu na medição das peças de madeira serrada em largura e espessura, e na identificação e mensuração dos defeitos inerentes a matéria-prima e ao processo. A avaliação dos defeitos seguiu os procedimentos descritos na NBR 14806 (ABNT, 2002), a qual também foi utilizada como referência para o enquadramento das peças em classes de qualidade.

Para a avaliação dos dados de rendimento e dimensões das peças (largura e espessura), foi utilizado uma análise multifatorial, onde os valores encontrados foram submetidos a verificação dos pressupostos para a utilização da estatística paramétrica. Foi aplicado o teste de Kolmogorov-Smirnov e Bartlett para a avaliação da normalidade dos dados e da homogeneidade das variâncias. Posteriormente, foi utilizada a Análise de Variância e o Teste de Tukey a 95\% de probabilidade de acerto. Na análise das dimensões das peças, acrescentouse os valores máximo e mínimo obtidos em cada medição.

A avaliação da distribuição das peças de madeira serrada por classe de qualidade, dentro de cada classe diamétrica e método de desdobro, foi realizada de forma descritiva, quantificando o percentual e o número de peças, de acordo com os defeitos característicos.

\section{RESULTADOS E DISCUSSÃO}

\section{Rendimento do processo de desdobro}

A análise de variância, Tabela 2 , demonstrou haver influência significativa $(P<0,05)$ da classe diamétrica e da interação classe diamétrica com o método de desdobro no rendimento do desdobro das toras. Porém, o método de desdobro de forma isolada não afetou o rendimento.

Tabela 2 - Análise de variância para o rendimento do desdobro.

\begin{tabular}{cc}
\hline Fonte de Variação & Rendimento bruto \\
\hline Classe diamétrica (CD) & $0,0004^{*}$ \\
Sistema de desdobro (MD) & $0,8327^{\text {ns }}$ \\
CD x MD & $0,0176^{*}$
\end{tabular}

Legenda: CD: classe diamétrica; MD: método de desdobro; * diferença estatística significativa, ${ }^{\text {ns }}$ ausência de diferença significativa, ambos pelo Teste de Tukey.

A influência das classes diametricas também foi verificada por Anjos \& Fontes (2017) ao avaliar espécies do gênero Eucalyptus spp. e por Scanavaca Junior \& Garcia (2003) no estudo com E. urophylla. Os autores afirmam que o maior diâmetro da ponta fina da tora, juntamente com a menor conicidade e a melhor uniformidade do fuste, proporcionam maior volume de peças de madeira serrada, em função do maior aproveitamento da tora durante o corte, tendo 
como consequência, a obtenção de um maior número de peças e /ou peças mais largas, as quais apresentam um maior valor agregado no momento da venda. Wade et al. (1992) cita que o rendimento em madeira serrada também é aumentado com o diâmetro das toras, devido ao menor volume de toras perdido com costaneiras e aparas.

Comportamento contrário, foi descrito por Del Menezzi \& Nahuz (1998) com E. grandis com 12 anos e por Cunha et al. (2015) com E. benthamii com 13 anos. Os autores salientam que além do diâmetro e da qualidade da tora, existem outros fatores que interferem no rendimento em madeira serrada, como o método de desdobro empregado e os equipamentos utilizados nas operações de corte.

A ausência de diferença significativa entre os métodos de desdobro tangencial e radial também foi verificada por outros autores como Juizo et al. (2014), ao estudar a madeira de espécies do gênero Eucalyptus spp. com 27 anos, Rocha (2000) com E. grandis e E. dunnii com 12 anos e 16,5 anos, respectivamente, e Cunha et al. (2015) com E. benthamii com 13 anos de idade. Este comportamento pode ser explicado pelo não aproveitamento das quatro costaneiras, as quais apresentavam espessura reduzida, e pelo número equivalente de cortes no processo de resserragem nas peças. Cabe salientar, que no desdobro tangencial, o semibloco foi resserrado de forma simultânea, ou seja, este método, provavelmente, apresentará uma maior produtividade, quando comparado com o desdobro radial, com dois semi-blocos por tora, e consequentemente um maior tempo de resserragem no processamento das duas partes.

Quanto à interação classe diamétrica e método de desdobro, observa-se diferença significativa, que pode ser atribuída ao maior volume de peças de madeira serrada das toras de maior diâmetro e a obtenção de peças mais largas, que é característico do desdobro tangencial. Outro fator a ser levado em consideração é o fato de que toras mais finas são provenientes de porções mais elevadas do fuste, tendo assim uma maior conicidade e resultando em um menor aproveitamento.

Os valores médios, apresentados na Tabela 3, são referentes aos rendimentos obtidos no processamento das toras das quatro classes diamétricas, desdobradas por meio de dois métodos de desdobro. Tomando-se como referência a análise de variância e o Teste de Tukey, constata-se, diferenças significativas entre a classe com maior diâmetro (D) e as demais ( $A, B, C)$, que foram equivalentes no rendimento pelo desdobro tangencial, enquanto que, para o radial, houve diferença significativa somente entre as classes A e D. Quanto ao método de desdobro dentro de cada classe diamétrica, observa-se equivalência no rendimento.

Tabela 3 - Rendimento do desdobro por classe diamétrica e método de desdobro (\%).

\begin{tabular}{|c|c|c|}
\hline Classe diamétrica & Desdobro tangencial & Desdobro radial \\
\hline$A$ & $48,51 \mathrm{Ba}$ & $44,40 \mathrm{Ba}$ \\
\hline $\mathrm{B}$ & $49,57 \mathrm{Ba}$ & $53,49 \mathrm{ABa}$ \\
\hline $\mathrm{C}$ & $50,53 \mathrm{Ba}$ & $54,46 \mathrm{ABa}$ \\
\hline $\mathrm{D}$ & $67,16 \mathrm{Aa}$ & $65,89 \mathrm{Aa}$ \\
\hline Média & 53,95 & 54,57 \\
\hline Média & \multicolumn{2}{|c|}{54,76} \\
\hline
\end{tabular}

Legenda: Classe diamétrica A: 23,7 a 30,6 cm; B: 30,7 a 34,8cm; C: 34,9 a 40,7 cm; D: 40,8 a 54,5 cm. Médias seguidas de mesma letra maiúscula na coluna / letra minúscula na linha não diferem estatisticamente pelo Teste de Tukey.

O rendimento médio obtido na transformação das toras de $E$. benthamii em peças de madeira serrada foi de 54,76\% (Tabela 3), o qual foi equivalente a espécies do mesmo gênero com diâmetros equivalentes, como em Carvalho \& Nahuz (2001) com o hibrido E. grandis $x$ E. urophylla (56,43\%), Amparado et al. (2008) com E. saligna $(52,77 \%)$ e Cunha et al. (2015) com E. benthamii (54,2\%); e superior a E. grandis (48,55\%), E. dunnii (49,32\%) e E. saligna (53,55\%) do estudo de Anjos \& Fontes (2017). 
No método de desdobro tangencial, observa-se um incremento de $1 \%$ no rendimento entre as classes A e B, e entre B e C, ou seja, equivalência. No entanto, quando se compara a classe $C$ com a classe $D$, tem-se um aumento de 16,6\%, o qual foi significativo em relação aos anteriores. Trabalhos como o de Ferreira et al. (2004), ao analisarem a influência de métodos de desdobro tangenciais para o gênero Eucalyptus spp. com idade média de 14 anos, tiveram a mesma tendência de aumento no rendimento nas maiores classes de desdobro.

Para o método de desdobro radial, verifica-se uma amplitude maior na diferença de rendimento bruto para as classes A e B (9\%), uma similaridade entre as classes B e C (1\%), e um aumento considerável da classe C para a D (11\%); no entanto, somente as classes A e D foram estatisticamente diferentes.

Em relação aos métodos de desdobro, Rocha (2000), também observou rendimentos equivalentes. Para o autor, que trabalhou com $E$. grandis e $E$. dunnii com 12 anos, o rendimento obtido no tangencial foi de 43,19\%, enquanto que no radial, 43,94\%. Outros, como Müller (2013) e Cunha et al (2015) para E. benthamii com 6 anos e 13 anos, verificaram uma superioridade do tangencial, principalmente para as classes com maior diâmetro.

Em termos industriais, o método de desdobro tangencial, otimiza o processo, demandando menor tempo de corte, por não se fazer necessário tanta movimentação das toras nos equipamentos. Segundo Vermaas (1995), o desdobro tangencial é preferido na Austrália por apresentar melhor desenho e maior rendimento. Rocha \& Tomaselli (2002) destacam que esse método apresenta também a vantagem de permitir que o empenamento apresentado pelas tábuas seja mais facilmente corrigido do que o apresentado pelas tábuas radiais.

\section{Rendimento do processo de desdobro por classe de qualidade}

Na Tabela 4, estão apresentados os percentuais de peças que podem ser aproveitados em cada uma das classes de qualidade e em cada método de desdobro aplicado, bem como o número total de peças obtidas no desdobro das toras. As características para o enquadramento das peças em cada uma das classes de qualidade, que foram determinadas por meio dos defeitos naturais e de processo, estão apresentadas na Tabela 5.

Tabela 4 - Peças de madeira serrada por classe de qualidade.

\begin{tabular}{|c|c|c|c|c|c|c|c|}
\hline \multirow{3}{*}{ CD } & \multirow{3}{*}{ MD } & \multicolumn{5}{|c|}{$\begin{array}{c}\text { Classes de qualidade (NBR14806, Associação Brasileira de } \\
\text { Normas Técnicas, 2002) }\end{array}$} & \multirow{3}{*}{ Total } \\
\hline & & 1 & 2 & 3 & 4 & 5 & \\
\hline & & \multicolumn{5}{|c|}{ Porcentagem de peças por classe } & \\
\hline \multirow{2}{*}{ A } & TG & $6,67_{(02)}$ & $6,67_{(02)}$ & $3,33_{(01)}$ & $50,00_{(15)}$ & $33,33_{(10)}$ & $100_{(30)}$ \\
\hline & $\mathrm{RD}$ & $2,50_{(1)}$ & $0,00_{(0)}$ & $7,50_{(3)}$ & $75,00_{(30)}$ & $15,00_{(6)}$ & $100_{(40)}$ \\
\hline \multirow{2}{*}{$\mathrm{B}$} & TG & $15,79_{(6)}$ & $21,05_{(8)}$ & $15,79_{(6)}$ & $21,05_{(8)}$ & $26,32_{(10)}$ & $100_{(38)}$ \\
\hline & $\mathrm{RD}$ & $1,82_{(1)}$ & $20,00_{(11)}$ & $5,45_{(3)}$ & $50,91_{(28)}$ & $21,82_{(12)}$ & $100_{(55)}$ \\
\hline \multirow{2}{*}{ C } & TG & $2,38_{(1)}$ & $4,76_{(2)}$ & $4,76_{(2)}$ & $45,24_{(19)}$ & $45,24_{(19)}$ & $100_{(42)}$ \\
\hline & $\mathrm{RD}$ & $10,67_{(8)}$ & $10,67_{(8)}$ & $6,67_{(5)}$ & $46,67_{(35)}$ & $25,33_{(19)}$ & $100_{(75)}$ \\
\hline \multirow{2}{*}{$\mathrm{D}$} & TG & $1,75_{(1)}$ & $0,00_{(0)}$ & $1,75_{(1)}$ & $40,35_{(23)}$ & $56,14_{(32)}$ & $100_{(57)}$ \\
\hline & $\mathrm{RD}$ & $4,88_{(4)}$ & $1,22_{(1)}$ & $3,66_{(3)}$ & $34,15_{(28)}$ & $56,10_{(46)}$ & $100_{(82)}$ \\
\hline \multirow{3}{*}{ Média } & TG & $6,65_{(10)}$ & $8,12_{(12)}$ & $6,41_{(10)}$ & $39,16_{(65)}$ & $40,26_{(71)}$ & $100_{(161)}$ \\
\hline & $\mathrm{RD}$ & $4,97_{(14)}$ & $7,97_{(20)}$ & $5,82_{(14)}$ & $51,68_{(121)}$ & $29,56_{(83)}$ & $100_{(242)}$ \\
\hline & Geral & $5,96_{(24)}$ & $8,05_{(32)}$ & $6,12_{(24)}$ & $45,42_{(186)}$ & $34,91_{(154)}$ & $100_{(403)}$ \\
\hline
\end{tabular}

Legenda: CD: classe diamétrica; MD: método de desdobro; TG.: tangencial; RD: radial; Classe diamétrica A: 23,7 a 30,6 cm; B: 30,7 a 34,8 cm; C: 34,9 a 40,7 cm; D: 40,8 a 54,5cm; valores entre parênteses: quantidade de peças. 
Tabela 5 - Características dos defeitos por classe de qualidade

\begin{tabular}{|c|c|c|c|}
\hline CD & CQ & MD & Peças por classe de qualidade (\%) \\
\hline \multirow{8}{*}{ A } & \multirow{2}{*}{2} & TG & $100 \% \mathrm{NF}$ \\
\hline & & $\mathrm{RD}$ & ----- \\
\hline & \multirow{2}{*}{3} & TG & $100 \% \mathrm{FE}$ \\
\hline & & $\mathrm{RD}$ & $100 \% \mathrm{FE}$ \\
\hline & \multirow{2}{*}{4} & TG & $15 \% \mathrm{FE}, 46 \% \mathrm{NC} ; 38 \% \mathrm{VR}$ \\
\hline & & $\mathrm{RD}$ & $3 \% \mathrm{FE} ; 27 \% \mathrm{NC} ; 63 \% \mathrm{VR} ; 7 \% \mathrm{AQ}$ \\
\hline & \multirow{2}{*}{5} & TG & $50 \% \mathrm{FE} ; 40 \% \mathrm{NC} ; 10 \% \mathrm{VR}$ \\
\hline & & $\mathrm{RD}$ & $33 \% \mathrm{FE} ; 33 \% \mathrm{NC} ; 33 \% \mathrm{VR}$. \\
\hline \multirow{8}{*}{$\mathrm{B}$} & \multirow{2}{*}{2} & TG & $100 \% \mathrm{NF}$ \\
\hline & & $\mathrm{RD}$ & $27 \% \mathrm{FE} ; 73 \% \mathrm{NF}$ \\
\hline & \multirow{2}{*}{3} & TG & $100 \% \mathrm{FE}$ \\
\hline & & $\mathrm{RD}$ & $100 \% \mathrm{FE}$ \\
\hline & \multirow{2}{*}{4} & TG & $8 \% \mathrm{FE} ; 31 \% \mathrm{NC} ; 62 \% \mathrm{VR}$ \\
\hline & & $\mathrm{RD}$ & $36 \%$ FE; $29 \%$ NC; 36\% VR \\
\hline & \multirow{2}{*}{5} & TG & $8 \% \mathrm{FE} ; 31 \% \mathrm{NC} ; 62 \% \mathrm{VR}$ \\
\hline & & $\mathrm{RD}$ & $50 \% \mathrm{FE} ; 42 \% \mathrm{NC} ; 8 \% \mathrm{VR}$ \\
\hline \multirow{8}{*}{$\mathrm{C}$} & \multirow{2}{*}{2} & TG & $50 \% \mathrm{FE} ; 50 \% \mathrm{NF}$ \\
\hline & & $\mathrm{RD}$ & $50 \% \mathrm{FE} ; 29 \% \mathrm{NF} ; 43 \% \mathrm{AQ}$ \\
\hline & \multirow{2}{*}{3} & TG & $100 \% \mathrm{FE}$ \\
\hline & & $\mathrm{RD}$ & $100 \% \mathrm{FE}$ \\
\hline & \multirow{2}{*}{4} & TG & $11 \% \mathrm{FE} ; 42 \% \mathrm{NC} ; 42 \%$ VR; $5 \%$ NS \\
\hline & & $\mathrm{RD}$ & $19 \%$ NC; $81 \%$ VR \\
\hline & \multirow{2}{*}{5} & TG & $38 \% \mathrm{FE} ; 25 \% \mathrm{NC} ; 31 \% \mathrm{VR} ; 6 \%$ NS \\
\hline & & $\mathrm{RD}$ & $22 \% \mathrm{FE} ; 39 \% \mathrm{NC} ; 39 \%$ VR \\
\hline \multirow{8}{*}{$\mathrm{D}$} & \multirow{2}{*}{2} & TG & ---- \\
\hline & & $\mathrm{RD}$ & $100 \% \mathrm{NF}$ \\
\hline & \multirow{2}{*}{3} & TG & $100 \% \mathrm{FE}$ \\
\hline & & $\mathrm{RD}$ & $100 \% \mathrm{FE}$ \\
\hline & \multirow{2}{*}{4} & TG & $30 \% \mathrm{NC} ; 70 \% \mathrm{VR}$ \\
\hline & & $\mathrm{RD}$ & $4 \% \mathrm{FE} ; 18 \%$ NC; $71 \%$ VR; $7 \%$ NS \\
\hline & \multirow{2}{*}{5} & TG & $25 \% \mathrm{NC} ; 75 \% \mathrm{VR}$ \\
\hline & & $\mathrm{RD}$ & $20 \% \mathrm{FE} ; 2 \% \mathrm{NC} ; 76 \%$ VR; $2 \%$ NS \\
\hline
\end{tabular}

Legenda: $\mathrm{CD}$ : classe diamétrica; $\mathrm{CQ}$ : classe de qualidade; MD: método de desdobro; TG: tangencial; RD: radial; Classe diamétrica A: 23,7 a $30,6 \mathrm{~cm}$; B: 30,7 a 34,8 cm; C: 34,9 a 40,7 cm; D: 40,8 a 54,5cm; NF: nó firme; NC: nó cariado; VR: veios de resina; NS: nó solto; FE: fendilhado; AQ: arqueamento.

Na Tabela 4, observa-se um maior percentual de peças de madeira serrada nas classes 4 e 5, independentemente se foram originadas do desdobro pelo método tangencial ou radial, ou pelas diferentes classes diamétricas. As características para enquadramento nas classes supracitadas são a alta incidência de nós cariados, veios de resina e fendilhamento.

$\mathrm{Na}$ classe 1, que é caracterizada por peças totalmente livre de defeitos, foram enquadradas somente 24 peças, de um total de 403 , o que representa somente 5,96\%. Destas, 10 peças são tangenciais $(6,65 \%)$ e 14 são radiais (4,97\%). Não se observa nesta classe, um aumento do número de peças com o aumento do diâmetro das toras. No entanto, nas classes diamétricas menores ( $A$ e $B$ ), houve um maior percentual de peças tangenciais, e nas maiores (C e D), de peças radiais. O baixo percentual e número de peças na classe 1, pode ser derivado da falta de tratos silviculturais aplicados, tendo em vista que a única atividade realizada, foi uma adubação na cova com NPK, momentos antes do plantio da muda.

Nas classes 2 e 3, os percentuais e o número de peças continuam baixos, com média geral abaixo de $9 \%$, tanto para o tangencial, quanto para o radial. Da mesma forma que a classe 1, não se observa uma tendência com o aumento do diâmetro das toras, no entanto, 
nas classes avaliadas, não se verifica uma diferença uniforme entre os métodos de desdobro tangencial e radial.

As peças classificadas como qualidade 2 apresentavam características como a presença de nós firmes com comprimento de $25 \mathrm{~mm} / \mathrm{m}$ e de fendilhamento em até $100 \mathrm{~mm} / \mathrm{m}$, enquanto que, para a qualidade 3, todas as peças apresentaram, exclusivamente, fendilhamento superior a $300 \mathrm{~mm} / \mathrm{m}$.

As classes 4 e 5, que são compostas pelas peças com o maior número de defeitos, ou seja, de menor valor agregado, apresentam o maior percentual, com médias gerais de $45,42 \%$ para a classe 4 e 34,91\% para a 5. Para a classe 4, os principais defeitos encontrados nas peças foi a presença de fendilhamento com comprimento de até $500 \mathrm{~mm} / \mathrm{mm}$, nó solto, nó cariado e veios de resina em até $25 \mathrm{~mm} / \mathrm{m}$. Para a classe 5, observa-se os mesmos defeitos da anterior, no entanto, sem limite de comprimento, ou seja, são aceitas todas as peças que não foram enquadradas nas anteriores.

A presença de defeitos como nós, principalmente os cariados, qualitativamente, tem como consequência a redução da resistência das peças. Kretschmann (2010) afirmou que os efeitos sobre a resistência da madeira dependem da proporção ocupada pelo nó na tábua e localização do nó, além da distribuição de esforços na peça. O mesmo autor relaciona a quantidade de nós cariados com a falta ou inexistência de tratos culturais para o plantio em questão, assim como, a consequente quebra natural dos galhos, fato este, associado ao processo de deterioração por fungos e insetos.

Segundo Foelkel (2010) a poda ou desrama em espécies do gênero Eucalyptus é feita com a finalidade de reduzir ao mínimo a incidência de nós na madeira. Apesar de ser impossível eliminar os ramos das árvores e sempre se ter que conviver com alguns nós, pode-se conseguir que eles se concentrem em uma região central no fuste, mais próximo da medula. O mesmo autor ainda diz que a primeira poda costuma ser feita quando o povoamento possui cerca de 1,5 anos de idade, se podando 50\% das melhores árvores, a segunda, quando as árvores estiverem com 10 a 12 metros de altura e a terceira quando estas, já estiverem com altura de 15 a 20 metros, tendo ao final do processo em média de 1,5 a 2,0 $\mathrm{m}^{3}$ de madeira livre de qualquer tipo de nó em cada tora.

A desrama, no caso deste estudo, não foi realizada em nenhum momento durante o desenvolvimento das árvores, justificando a elevada quantidade de nós, principalmente os cariados presentes nas peças das classes 4 e 5.

O fendilhamento, que foi encontrado em peças de todas as classes, mas em grande percentual nas classes 2 e 3, é decorrente do:

- $\quad$ processo de derrubada, em função do grande peso das árvores, que podem fendilhar quando caem no chão, e das tensões de crescimento que são forças que se originam na região cambial do tronco durante a fase de maturação das células, em que elas tendem a se contrair longitudinalmente e se expandir transversalmente (Lima et al., 2000). No entanto, este último, tende a ser menos expressivo, em função de se tratar de árvores com 23 anos;

- do longo processo de armazenamento, cerca de 2 meses, em função da disponibilidade de transporte e desdobro na serraria; nesta etapa, acredita-se que as toras que já apresentavam algum fendilhamento, aumentaram os seus comprimento, devido as oscilações de temperatura e umidade relativa do local;

- $\quad$ do desdobro, que não foi realizado de forma simultânea nos dois primeiros cortes do desdobro primário, e sim em uma serra fita simples de forma alternada. Segundo Lima et al. (2000), os fendilhamentos estão ligados a gradientes de umidade existentes ao longo da tora o qual pode ter existido pelo tempo de armazenagem das toras no local de corte.

Os veios de resina, também chamados de bolsa de kino ou de gomose do eucalipto, que foram muitos frequentes nas peças classificadas com qualidade 4 e 5 , são muito comuns em condições subtropicais e tropicais (Tippett, 1986), manifestando-se como um escurecimento dos troncos das árvores, o que é causado pela exudação de um líquido avermelhado que contém uma quantidade maior de polifenóis do que de carboidratos. O autor cita também, 
que o aparecimento deste defeito é comum em períodos de seca prolongado, em plantios que foram atingidos por fogo ou algum dano mecânico, e plantios que tiveram grande incidência de patógenos como fungos e insetos. Ferreira (1989) também menciona que o defeito é decorrente de problemas fisiológicos como mudanças bruscas de temperaturas e falta de nutrientes no solo, sendo mais comum em espécies como E. citriodora, E. maculata, E. paniculata e algumas procedências de $E$. grandis.

O plantio experimental, de onde foram retiradas as árvores para o estudo é caracterizado por um solo pobre, uma vez que solos distróficos são tidos como de caráter ácido, rasos, de média e baixa fertilidade e com baixa quantidade de cálcio. Aliado a esta situação, pode-se mencionar a falta de adubação que pudesse suprir tal deficiência. Desta forma, pode-se dizer que a presença dos veios de resina em grande parte das peças foi devido ao solo onde as árvores foram plantadas e a falta de uma condução silvicultural mais específica.

\section{Dimensões das peças após o desdobro}

Na Tabela 6, pode-se observar um incremento dos valores de largura, com o aumento do diâmetro das toras. Entretanto, quando se observa o método de desdobro dentro cada classe diamétrica, o tangencial apresenta as maiores larguras em todas as classes. Outro ponto que pode ser destacado na tabela, é o alto coeficiente de variação, que tem uma amplitude de $16,21 \%$ a $38,21 \%$.

Tabela 6 - Largura e espessura das peças de madeira serrada após o desdobro.

\begin{tabular}{|c|c|c|c|c|}
\hline \multirow{2}{*}{ CD } & \multicolumn{2}{|c|}{ Largura das peças (mm) } & \multicolumn{2}{|c|}{ Espessura da peças (mm) } \\
\hline & TG & RD & TG & RD \\
\hline A & 169165,13159 & 8785,0792 & 3433,5032 & $3333,10_{32}$ \\
\hline A & $(38,21) \mathrm{Ca}$ & $(23,65) \mathrm{Cb}$ & $(7,34) \mathrm{Aa}$ & $(24,12) \mathrm{Aa}$ \\
\hline $\mathrm{B}$ & 207200,71196 & 127123,55119 & 3433,1031 & 3231,9031 \\
\hline$D$ & $(17,98) \mathrm{Ba}$ & $(25,32) \mathrm{Bb}$ & $(12,42) \mathrm{Aa}$ & $(20,29) \mathrm{Aa}$ \\
\hline $\mathrm{C}$ & 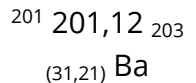 & $\begin{array}{c}135131,10129 \\
(16,21) \mathrm{Bb}\end{array}$ & $\begin{array}{c}34 \mathrm{33}^{3,40} 32 \\
(8,45) \mathrm{Aa}\end{array}$ & $\begin{array}{c}333_{2}, 70_{31} \\
(17,23) \mathrm{Aa}\end{array}$ \\
\hline $\mathrm{D}$ & $\begin{array}{c}229227,13223 \\
(26,72) \mathrm{Aa}\end{array}$ & $\begin{array}{c}164162,56160 \\
(23,87) A b\end{array}$ & $\begin{array}{c}3433,300_{31} \\
(7,81) \mathrm{Aa}\end{array}$ & $\begin{array}{c}3433,8032 \\
(25,43) \mathrm{Aa}\end{array}$ \\
\hline
\end{tabular}

Legenda: CD: classe diamétrica; TG: tangencial; RD: radial; Classe diamétrica A: 23,7 a 30,6 cm; B: 30,7 a 34,8 cm; C: 34,9 a 40,7 cm; D: 40,8 a 54,5 cm; sobrescritos e subscritos: largura / espessura superior e inferior; subscritos e entre parênteses: coeficiente de variação. Médias seguidas de mesma letra maiúscula na coluna / letra minúscula na linha não diferem estatisticamente pelo Teste de Tukey.

O aumento da largura com o incremento do diâmetro das toras e as diferenças significativas observadas entre desdobro tangencial e radial, também foram observados por Rocha \& Tomaselli (2002), ao avaliar o efeito de dois modelos de corte (radial e tangencial), duas classes diamétricas para E. grandis de 12 anos e Eucalyptus dunnii de 16,5 anos. Segundo os autores, o desdobro radial proporcionou um número maior de peças, mas com menores larguras, devido as toras serem cortadas ao meio no desdobro primário, o que limita a dimensão, tanto que, a aplicação deste método acaba se justificando somente para toras com alto valor agregado e/ou grandes diâmetros. Esta situação, também é mencionada por Fagundes (2003), onde cita que a utilização de peças no sentido radial pode ser facilmente empregada em toras mais grossas, se tornando pouco viável em toras com diâmetros menores, devido a quantidade de subdivisões necessárias para a obtenção de peças com superfícies verdadeiramente radiais.

Para espessura das peças, Tabela 6 , observa-se que a classe diamétrica e o método de desdobro não influenciaram nos resultados, com amplitude de 31,00 a $34,00 \mathrm{~mm}$. No entanto, constata-se valores maiores do que a espessura nominal, o que é decorrente do ajuste ineficiente da serra circular no desdobro secundário. 


\section{CONCLUSÃO}

$O$ rendimento do processo de desdobro das toras de $E$. benthamii em madeira serrada foi influenciado de forma significativa pela classe diamétrica, sendo que, quanto maior o diâmetro das toras, maiores foram os rendimentos. O método de desdobro influenciou somente quando em interação com a classe diamétrica.

O rendimento médio do desdobro foi de $54,76 \%$, sendo que as peças de madeira serrada foram classificadas, em sua maioria, nas classes 4 e 5, segundo parâmetros da NBR 14806 (ABNT, 2002).

Nas dimensões das peças de madeira serrada, observou-se influência da classe diamétrica e do método de desdobro somente para a variável largura. Toras de maior diâmetro, desdobradas tangencialmente, proporcionaram mais largas.

A utilização de toras de E. benthamii no processo de desdobro mostrou-se viável em rotação longa, com rendimento equivalente a grande parte das espécies comerciais de rápido crescimento.

\section{AGRADECIMENTOS}

Os autores agradecem a Universidade do Estado de Santa Catarina - UDESC; a Empresa de Pesquisa Agropecuária e Extensão Rural de Santa Catarina (EPAGRI); e a Fundação de Amparo a Pesquisa e Inovação do Estado de Santa Catarina - FAPESC.

\section{REFERÊNCIAS BIBLIOGRÁFICAS}

Amparado, K. F., Carvalho, A. M., Garcia, R. A., \& Latorraca, J. V. F. (2008). Caracterização do rendimento em madeira serrada de Eucalyptus saligna Smith nas condições verde e seca. Forestal Venezolana, 52(1), 71-76.

Anjos, R. A. M., Fontes, A. P. N. (2017). Rendimento de madeira serrada de espécies de Eucalyptus. Ciências Agroveterinárias, 16(1), 26-32, https://doi.org/10.5965/223811711612017026.

Associação Brasileira de Normas Técnicas - ABNT. (2002). NBR 14806: Madeira serrada de eucalipto Requisitos. Rio de Janeiro: ABNT.

Carvalho, A. M., \& Nahuz, M. A. R. (2001). Valorização da madeira do híbrido Eucalyptus grandis x urophylla através da produção conjunta de madeira serrada em pequenas dimensões, celulose e lenha. Scientia Forestalis, 59(61), 61-76.

Cunha, A. B., França, M. C., Almeida, C. C. F., Gorski, L., Cruz, R. C., \& Santos, D. (2015). Avaliação do rendimento em madeira serrada de Eucalyptus benthamii e de Eucalyptus grandis por meio do desdobro tangencial e radial. Floresta, 45(2), 241-250. http://dx.doi.org/10.5380/rf.v45i2.32570.

De Vechi, A., \& Magalhães Júnior, C. A. O. (2018). Aspectos positivos e negativos da cultura do eucalipto e os efeitos ambientais do seu cultivo. Revista Valore, 3(1), 495-507. http://dx.doi.org/10.22408/reva312018101495-507.

Del Menezzi, C. H. S., Nahuz, M. A. R. (1998). Técnicas de desdobro utilizadas para madeira de eucalipto - uma revisão de literatura. Árvore, 22(3), 415-428.

Fagundes, H. A. V. (2003). Produção de madeira serrada e geração de resíduos do processamento de madeira de florestas plantadas no Rio Grande do Sul (Dissertação de mestrado). Universidade Federal do Rio Grande do Sul, Porto Alegre.

Ferreira, A. G., Paes, J. B., Melo, R. R., \& Guedes, R. S. (2004). Consumo das madeiras de Eucalyptus grandis, E. pilularis e E. saligna x E. alba (híbrido) por cupins xilófago. In Anais do Congresso de Iniciação Científica da Universidade Federal de Campina Grande. Campina Grande: UFCG.

Ferreira, F. A. (1989). Patologia florestal: principais doenças florestais no Brasil (pp. 34-37). Viçosa: UFV/SIF.

Foelkel, C. (2010). Poda ou desrama das árvores dos Eucaliptos. Eucalyptus Online Book and Newsletter, 25.

Higa, R. C. V., \& Pereira, J. C. D. (2003). Usos potenciais do Eucalyptus benthamii Maiden (Comunicado Técnico Embrapa, Vol. 1, No. 2). Colombo, PR: Embrapa.

Juizo, C. G. F., Rocha, M. P., \& Bila, N. F. B. (2014). Avaliação do rendimento em madeira serrada de eucalipto para dois modelos de desdobro numa serraria portátil. Floresta e Ambiente, 21(4), 543550. http://dx.doi.org/10.1590/2179-8087.062213. 
Kretschmann, D. E. (2010). Mechanical properties of wood. In: United States Department of Agriculture USDA. Wood handbook: wood as an engineering material. Madison: USDA, Forest Service.

Lima, J. T., Breese, M. V., \& Cahalan, C. M. (2000). Variation in wood density and mechanical properties in Eucalyptus clones. In: Anais do IUFRO conference: the future of Eucalyptus for wood products. Launceston: IUFRO.

Müller, B. V. (2013). Efeito de sistemas de desdobro na qualidade e rendimento de madeira serrada de Eucalyptus benthamii Maiden et Cambage (Dissertação de mestrado). Universidade Federal do Paraná, Curitiba.

Rocha, M. P. (2000). Eucalyptus grandis Hill ex Maiden e Eucalyptus dunii Maiden como fontes de matériaprima para serrarias (Tese de doutorado). Universidade Federal do Paraná, Curitiba.

Rocha, M. P., \& Tomaselli, I. (2002). Efeito do modelo de desdobro na qualidade da madeira serrada de Eucalyptus grandis e Eucalyptus dunnii. Cerne, 8(2), 70-83.

Scanavaca Junior, L., \& Garcia, J. N. (2003). Rendimento em madeira serrada de Eucalyptus urophylla. Scientia Forestalis, 63, 32-43.

Silva, J. C. (2002). Caracterização da madeira de Eucalyptus grandis Hill ex. Maiden, de diferentes idades, visando a sua utilização na indústria moveleira (Tese de doutorado). Universidade Federal do Paraná, Curitiba.

Silva, L. D., Higa, A. R., \& Santos, G. A. (2012a). Desafios do Uso da Madeira de Eucalyptus benthamii para Serraria. In L. D. Silva, A. R. Higa, \& G. A. Santos (Eds.), Silvicultura e melhoramento genético de Eucalyptus benthamii (pp. 123-150). Curitiba: Editora FUPEF.

Silva, L. D., Higa, A. R., \& Santos, G. A. (2012b). Potencial da silvicultura clonal de Eucaplyptus benthamii para o Sul do Brasil. In L. D. Silva, A. R. Higa, \& G. A. Santos (Eds.), Silvicultura e melhoramento genético de Eucalyptus benthamii (pp. 77-103). Curitiba: FUPEF.

Tippett, J. T. (1986). Formation and fate of kino veins in Eucalyptus L'Herit. IAWA Bulletin, 7(2), 137-143. http://dx.doi.org/10.1163/22941932-90000975.

Vermaas, H. F. (1995). Drying eucalypts for quality: material characteristics, predrying treatments, drying methods, schedules and optimization of drying quality. In Anais do Seminário Internacional de Utilização da Madeira de eucallpto para serraria. São Paulo: IPEF/IPT/UFRO/ESALQ/USP. http://dx.doi.org/10.1080/00382167.1995.9629877.

Wade, M. W., Bullard, S. H., Steele, P. H., \& Araman, P. A. (1992). Estimating hardwood sawmill conversion efficiency based on sawing machine and log characteristics. Forest Products Journal, $42(11-12), 21-26$.

Contribuição dos Autores: GFT: conceituação, curadoria dos dados, análise formal, investigação, metodologia, administração do projeto, escrita - primeira redação, escrita - revisão e edição; ABC: conceituação, curadoria dos dados, análise formal, investigação, metodologia, supervisão, escrita - primeira redação, escrita - revisão e edição: MAB: conceituação, análise formal, metodologia, escrita - primeira redação, escrita - revisão e edição; UAC: conceituação, análise formal, recursos, validação, escrita - primeira redação. 